next day by his senior colleagues. The nursing staff are well versed in the clinical practices and foibles of the latter, and part of the patient's emergency assessment seems to be to find out which consultant will be responsible for his care in order to avoid any form of management that he might consider inappropriate. If the developing clinical skill and competence of a junior doctor is seen as similar to the emerging sexual potency of a child, then 'cutting remarks' about inappropriate emergency treatment may represent a symbolic castration, echoing oedipal conflicts and castration anxiety (Freud, 1977). A second oedipal anxiety is that the infant's tiny organ will be insufficient to meet the fantasised sexual needs of his mother; perhaps this is reflected in the anxiety that an emergency will arise while 'on-call' that will be too difficult to manage, and to the doctor's chagrin, will overwhelm his clinical skills.

Being on-call can, of course, be stressful and exhausting, when one is 'busy' or when continuous hard work extends for days without respite. It is then that the on-call doctor decides that all his problems are the fault of GPs for inappropriate referrals or for leaving real pathology unattended too long. Or that the 'real problem' lies in the hospital management, the nursing staff or indeed any other group that does not include him. When practising GPs work in the acute hospital setting, they are much more understanding of the problems that face those working in primary care when deciding whether or not a patient requires an emergency hospital referral. "But as for deputising doctors ...". The spectacle of a student nurse dashing about during an emergency resuscitation having been severely chided for forgetting some trivial instrument is a good example of projection in a situation of stress. The experience of being 'stretched' or 'at the end of one's tether' may echo the anxiety of the primative ego of disintegration, which is dealt with by projection into a 'bad object' - the so- called Paranoid-Schizoid position (Segal, 1981). The doctor unconsciously divides the hospital into two groups, say, doctors and nurses, then projects all the 'badness', onto the latter. If he is really lucky, the nurses will identify with the projection, and start apologising! While staff groups are able to protect themselves from these 'bad' projections, patients are not. A common group to be scapegoated is the acute medical situation are people who have overdosed or have alcohol-related problems; they demand much time and effort of busy staff, and yet their pathology is to some extent 'self inflicted'. Sadly, it may be that these are the most likely groups to identify with the doctor's projections, acting them out with further self-destructive behaviour.

I have argued that some of the anxiety aroused by the experience of being resident on-call may be caused by the echoing of unconscious conflicts encountered by the developing ego; leaving home, being called and making management decisions reflecting Freud's oral, anal and phallic stages respectively. I have suggested ways that these and primitive splitting and projection may affect the doctor's relationships with his colleagues and even his patients. Perhaps one way of guarding against these problems is to reduce the junior doctor's hours, but another is to remember the adage "physician, heal thyself" with the addition "and give due attention to thine unconscious conflicts while on-call".

\section{References}

ERIKSON, E. A. (1965) Childhood and Society (second edition). Harmondsworth: Penguin. pp. 239-266.

Freud, S. (1977) On Sexuality. Harmondsworth: Penguin. pp. 33-169, and pp. 315-322.

RYECROFT, C (1972) A Critical Dictionary of Psychoanalysis. Harmondsworth: Penguin. p. 109.

Segal, H. (1981) Melanie Klein. Harmondsworth: Penguin. pp. 113-124.

\title{
Dr Inayat Khan
}

Dr Inayat Khan, Chief Medical Officer at the Psychotropic and Narcotic Drugs Unit at WHO, and Fellow of the College, retired early this year. He worked for nearly 20 years at WHO serving the international community by providing an unbiased opinion on the public health and social problems associated with the use of dependence-producing psychoactive drugs, on the one hand, and their therapeutic usefulness on the other. He also worked to promote the rational use of these drugs, once they were registered and available for use. Over the years he visited many countries round the world to stimulate interest in the field, and will be greatly missed by the scientists, clinicians, and administrators with whom he worked. He will continue to live in Switzerland and we wish him happiness in his retirement. 